\title{
Determinants of effective vaccine coverage in low and middle-income countries: a systematic review and interpretive synthesis
}

\author{
David E. Phillips ${ }^{1 *}$, Joseph L. Dieleman ${ }^{1}$, Stephen S. Lim ${ }^{1}$ and Jessica Shearer ${ }^{2}$
}

\begin{abstract}
Background: Many children in low and middle-income countries remain unvaccinated, and vaccines do not always produce immunity. Extensive research has sought to understand why, but most studies have been limited in breadth and depth. This study documents existing evidence on determinants of vaccination and immunization and presents a conceptual framework of determinants.

Methods: We used systematic review, content analysis, thematic analysis and interpretive synthesis to document and analyze the existing evidence on determinants of childhood vaccination and immunization.

Results: We documented 1609 articles, including content analysis of 78 articles. Three major thematic models were described in the context of one another. Interpretive synthesis identified similarities and differences between studies, resulting in a conceptual framework with three principal vaccine utilization determinants: 1) Intent to Vaccinate, 2) Community Access and 3) Health Facility Readiness.

Conclusion: This study presents the most comprehensive systematic review of vaccine determinants to date. The conceptual framework represents a synthesis of multiple existing frameworks, is applicable in low and middle-income countries, and is quantitatively testable. Future researchers can use these results to develop competing conceptual frameworks, or to analyze data in a theoretically-grounded way. This review enables better research in the future, further understanding of immunization determinants, and greater progress against vaccine preventable diseases around the world.
\end{abstract}

\section{Background}

Childhood vaccinations are among the most effective and cost effective public health interventions available $[1,2]$. Yet, vaccine-preventable diseases caused approximately $14 \%$ of disability-adjusted life years (DALYs) in 2015 globally, and 15\% of DALYs in SubSaharan Africa [3].

Many children remain unimmunized. Global coverage of diphtheria-tetanus-pertussis (DTP3) vaccination ranges from $75 \%$ in Africa to $96 \%$ in Europe [4]. Despite progress, socio-economic inequalities persist as well [5]. Furthermore, vaccines do not always provide

\footnotetext{
* Correspondence: davidp6@uw.edu

${ }^{1}$ Institute for Health Metrics and Evaluation, University of Washington, Seattle, USA

Full list of author information is available at the end of the article
}

immunity. For example, vaccination against measles has been estimated to be $85 \%$ effective in the United States and 66\% effective in Mozambique [6, 7].

Extensive research efforts have been focused to understanding why vaccine coverage (vaccination) remains low, and why vaccines sometimes fail to produce immunity (immunization). Quantitative studies have sought to measure determinants using survey and other data. Systematic reviews have been published on both vaccination and immunization determinants in order to gather studies together [8-14]. Some have taken additional steps to develop a conceptual framework, i.e. general model for thinking about how determinants interoperate $[8,11]$. Others assess health systems, describing bottlenecks and constraints to successful vaccine delivery from the supply-side, for example by applying the World Health Organization's 
(WHO) Health Systems Building Blocks framework to new vaccine introductions [15-17].

Most studies and systematic reviews have been limited in breadth and depth however. Other authors have noted that studies seeking to directly measure determinants are rarely based on a grounded theoretical model such as a conceptual framework from systematic review $[11,18]$. Systematic reviews focusing on vaccine coverage have only covered a subset of the published research $[8,11]$. Reviews on vaccine effectiveness have not offered a complete account of potential determinants; they instead focus on a few important factors such as cold storage or administration [12-14]. Synthesis of a wide body of literature also faces challenges of combining heterogeneous study designs [19]. Previously proposed conceptual frameworks are often untestable in a quantitative sense, and therefore may have limited utility to independent researchers with new data to analyze $[8,11]$. Most conceptual frameworks rely on narrative description of determinants more than explicit depictions of the pathways and interactions through which they are thought to influence immunization [8-14].

Public health practitioners and vaccine researchers would benefit from a systematic review and synthesis of determinants research. A complete listing of previous studies would be valuable as a standalone resource, since one of the most challenging aspects of developing a conceptual framework is initially amassing all available information for synthesis. Efforts to make sense of the literature could yield useful hypotheses, even competing hypotheses, about how different determinants lead to immunization. Future studies could collect data to measure the hypothesized determinants, and model them to quantify their impact in a more grounded way. Interventions could leverage such information to target determinants of greater need and evaluate programs with outcomes that are fit for purpose to enhance their efforts to improve immunization around the world.

The objective of this study is to generate a conceptual framework of the determinants of effective coverage of childhood vaccines. This will summarize, as succinctly as possible, determinants of vaccine coverage, the determinants of vaccine effectiveness, and relationships between them, and represent them in the form of a testable hypothesis. Special emphasis will be placed on including determinants that are relevant in low and middle-income countries (LMICs). We accomplish the study objective by conducting a systematic review of reasons for non-vaccination and reasons for vaccine failure. We perform three qualitative analyses on the information in the review, using critical interpretive synthesis defined in Dixon-Woods et al. 2006 [20].

\section{Methods}

Protocol, registration and preliminary review

A pre-defined protocol was followed, detailed in Additional file 1. This protocol was unregistered. A preliminary review was first conducted to inform future searches and analyses. This was carried out in an unstructured manner, iteratively relying on Google Scholar search results, backward/forward citation searches, examination of highly-cited articles and expert input. Citation network diagrams were generated as an aid to locate works that web searches did not immediately uncover, but which other researchers often reference. Further details can be found in Additional file 1.

\section{Eligibility criteria}

Eligibility criteria were established in advance, using information from the preliminary review as a guide. Any English-language article that supplied evidence for at least one determinant of vaccine coverage or effectiveness was eligible for inclusion. Articles were excluded if they specifically pertained to any of the following topics without meeting the inclusion criterion: adult vaccines besides HPV, animal vaccines, levels and trends of coverage, consequences of utilization, health impact, highly-specific subpopulations (e.g. travelers, HIV-positive populations), vaccine effectiveness/efficacy/safety, disease treatment, pathobiology, future vaccines, cost effectiveness, general health care utilization, impact of a single intervention, vaccine manufacturing, promotion of a particular vaccine technology.

\section{Search}

A set of 112 potential search terms (mostly various synonyms) was developed based on the preliminary review, these terms are listed in Additional file 2. The search strategy was as follows:

1) Order the potential searches according to their expected propensity to return unique and relevant results

2) Enter the first search term into Google Scholar and review the first 500 titles, adding eligible citations to a database

3) Enter the next search term into Google Scholar, again reviewing the first 500 titles for inclusion

4) Count the proportion of new and duplicate articles identified by the present search

5) Repeat steps 3 and 4 until the duplication percentage exceeds $33 \%$ for three consecutive searches

6) Conduct two PubMed searches with multiple MeSH terms and screen results in their entirety.

By this procedure, 14 Google Scholar and 2 PubMed searches were conducted. In addition, six special databases were screened in their entirety with the keywords 
"Vaccine" and "Immunization". These databases were HealthSystemsEvidence.org, Cochrane Library, Journal of Systematic Reviews, Agency for HealthCare Research and Quality, Centre for Reviews and Dissemination and EPPI Centre [21-26]. Nine existing systematic reviews were discovered through this process, and their compete citation lists were also screened [9, 10, 13, 27-32].

\section{Study selection}

All eligible articles and documents were catalogued in a citation database and systematically evaluated for relevance to the present study's objectives. The objective of this stage was to organize the search results so that they could be analyzed in descending order of relevance.

Articles and documents were assigned a subjective relevance score (on a continuous scale ranging from $0-$ irrelevant to the present study, 1 - exactly on-topic) based on a set of five criteria, listed in Table 1. Relevance was determined using the title and abstract. An assessment by the reviewer was used to judge relevance across the five criteria. Although some criteria could be objectively assessed (for example "comprehensiveness" was assessed based on whether the authors of the study claimed to have explored an exhaustive list of determinants, or only focused on a subset), some degree of subjectivity was required on the part of the reviewer to assign relevance scores. Articles were assigned higher scores if all five criteria were aligned with the study's objectives, and lower scores if only some of the criteria were aligned with the study's objectives. 78 articles were determined to be highly-relevant and were selected for analysis.

\section{Data collection process}

Starting with the most relevant articles, the information therein was systematically extracted and stored in a database. The objectives of this stage were to find a subset of articles large enough to perform content analysis, thematic analysis and interpretive synthesis (see subsequent sections), and to itemize and understand the content of that subset of articles.

\section{Data items}

Fourteen variables were extracted from each study in selected set. Variables included study characteristics and content of study results and are listed in Table 1 . A colorcoding system was used, and all coded documents were stored digitally to ensure transparency and consistency between extractions. Data were extracted from the 78 selected articles in descending order of relevance.

\section{Risk of bias}

Risk of bias was assessed at the study-level. The primary characteristics assessed were comprehensiveness of determinants explored, emphasis of the study (whether determinants were the primary purpose of the study) and geography (subnational, national, sub-population). Bias was minimized by excluding non-comprehensive studies or studies which focused on specific sub-populations from the highly-relevant set of 78 articles. Because this study was primarily focused on understanding which determinants are represented in the literature (and not the strengths of their correlations), it was not deemed necessary to assess risk of bias in study results, for example due to selection, attrition, or detection.

Table 1 Systematic review criteria

\begin{tabular}{|c|c|c|c|}
\hline Inclusion & Exclusion & Relevance & Extraction \\
\hline \multirow[t]{3}{*}{ Supplies evidence for at least one determinant } & Adult vaccines besides HPV & Comprehensiveness & Country/region \\
\hline & Animal vaccines & Emphasis & Review \\
\hline & Levels and trends of coverage & Geography & Study design \\
\hline \multirow[t]{12}{*}{ English language } & Consequences of utilization & Novelty & Study population \\
\hline & Health impact & Outcomes & Related studies \\
\hline & Highly-specific subpopulations & & Antigen(s) \\
\hline & Vaccine effectiveness/efficacy/safety & & Outcome(s) \\
\hline & Disease treatment & & Determinant(s) \\
\hline & Pathobiology & & Exhaustive \\
\hline & Future vaccines & & Proximity \\
\hline & Cost effectiveness & & Pathway(s) \\
\hline & General health care utilization & & Effect size(s) \\
\hline & Impact of a single intervention & & Theme(s) \\
\hline & Vaccine manufacturing & & Thematic excerpts \\
\hline & Promotion of a particular vaccine technology & & \\
\hline
\end{tabular}




\section{Summary measures and content analysis}

The aims of this study were primarily qualitative in nature. Hence summary measures of study results were limited to the descriptions and lists of determinants provided by the authors.

Content analysis was performed to characterize the itemized determinants from data extraction $[19,33]$. The objective of this stage was to document and organize the data, specifically focusing on the determinants and pathways identified in the literature.

All discrete determinants mentioned in the extracted data were listed and systematically examined. This was done by maintaining a running list of determinants, resulting in concurrent, rather than sequential content analysis and data extraction. The list of determinants, as well as the text from which they were extracted, was repeatedly revisited to understand the context in which those determinants were described. Synonymous determinants and determinants with negligible conceptual differences (e.g. "not enough time" vs "too busy") were condensed into a common set of terms. Finally, a frequency table of determinants was created, and related pathways were explored, starting with the most frequently-cited determinants.

The output from this stage was represented in a path diagram intended to represent the universe of determinants, according to the literature.

\section{Synthesis of results}

In addition to content analysis, two qualitative methods were employed to synthesize across studies: Thematic Analysis and Critical Interpretive Synthesis.

\section{Thematic analysis}

Thematic analysis was carried out to document the broader qualitative groups (i.e. themes) within which determinants are hypothesized to reside $[19,33]$. The objectives of this stage were to describe the ways in which authors most commonly categorize determinants, and to bring together similar categorizations into a small number (three to five) of broad frameworks, termed thematic models.

Thematic analysis was accomplished by relying on the author descriptions. The categories they used to group determinants were listed along with excerpts of text in which they were described. Like content analysis, this step was conducted in an iterative fashion, seeking patterns between studies. It was anticipated that some studies would cite a more generalized sociological or health system theory as the source for their themes. In the event that multiple studies cited the same generalized theory those citations were also examined and included in the thematic analysis.

\section{Critical interpretive synthesis}

The third analysis was interpretive synthesis of the literature, following guidelines from Dixon-Woods et al. 2006 [20]. This stage entailed critical analysis of the determinants identified through content analysis and categorizations identified through thematic analysis. The objective of this phase was to formulate a conceptual framework that draws from other researchers' frameworks, and represent this framework in the form of a testable hypothesis. Critical interpretive synthesis was used in addition to thematic analysis in order to draw deeper understanding of the themes identified, and analyze the ways in which they were hypothesized to fit together. This approach was used because it details suitable a process for accomplishing the goal of generating a testable hypothesis [20].

Key methods in interpretive synthesis are known as reciprocal translational analysis (RTA), refutational synthesis and lines-of-argument synthesis (LOA), and are adapted from meta- ethnographical research [20, 34, 35]. RTA expands on the processes already described in the previous two sections (Thematic Analysis and Content Analysis). In short, RTA involves identifying broad concepts (themes) reported in each study, and identifying similarities between them. Refutational synthesis involves the opposite process; contradictions between studies (in terms of themes or descriptions of themes) are explored. This process lends insight to a conceptual framework by elucidating the gaps and discrepancies between studies in such a way that produces novel perspectives on common concepts. The final method (LOA) involves the most interpretive input on the part of the researcher. LOA entails integrating strongly-supported factors across studies and attempting to form a synthesizing argument, or a description of how they fit together, that is both succinct and understandable to commonplace audiences. The synthesizing argument often includes the generation of synthetic constructs, sometimes referred to as latent variables.

Information for interpretive synthesis came from multiple sources. Other studies which offered their own conceptual framework were used, as well as lessons from Thematic Analysis described above. In addition, broader theories which have been applied to describe health service utilization and health system strength were used $[15,36]$.

The ultimate testable hypothesis developed in this stage was also formulated through an iterative process, repeatedly revisiting previously-documented themes as new studies were examined (over the period of the review, see below) for further comparisons and contrasts. This stage also relied heavily on broader sociological and health systems theories to offer formalized and grounded structure $[15,36]$. 


\section{Additional analyses}

Besides those previously described, no additional analyses were performed.

\section{Results}

\section{Study selection}

A total of 35 web-searches were performed from February 2015 to May 2015, including Google Scholar (14 searches), PubMed (2 searches) special databases (9 searches) and backward citations (10 articles). In total, 9041 titles were examined for inclusion. Of those, 1621 eligible articles were identified, 12 studies were re-publications of another article (with a different name or publisher) and were excluded.

All 1609 included articles were assessed for relevance based on title and abstract, resulting in 78 highly relevant articles (relevance score $>0.9$ ), 389 moderately relevant articles (relevance score $>0.8$ and $<0.9$ ) and 1142 lessrelevant articles (relevance score $<0.8$ ). The complete list of 1609 citations can be found in Additional file 3, organized by relevance. Figure 1 displays a flow diagram of the search and selection.

\section{Study characteristics and content analysis}

Content was extracted from 78 articles, the characteristics of which are detailed in Additional file 3. A wide array of determinants was documented among the extracted articles, totaling 638 uniquely-worded factors such as travel time to health facility, various perceptions about vaccines, stockouts at health facilities and others. By iteratively revisiting the list of determinants and examining the context in which they were described, a condensed framework of 69 coverage determinants and 20 effectiveness determinants was developed. By examining the described pathways between determinants, 115 pathways of influence were identified, forming a comprehensive network of vaccine coverage. An additional 22 pathways of influence were identified for vaccine effectiveness. The complete network of effective coverage determinants are listed in Tables 2 and 3, and displayed visually in Fig. 2.

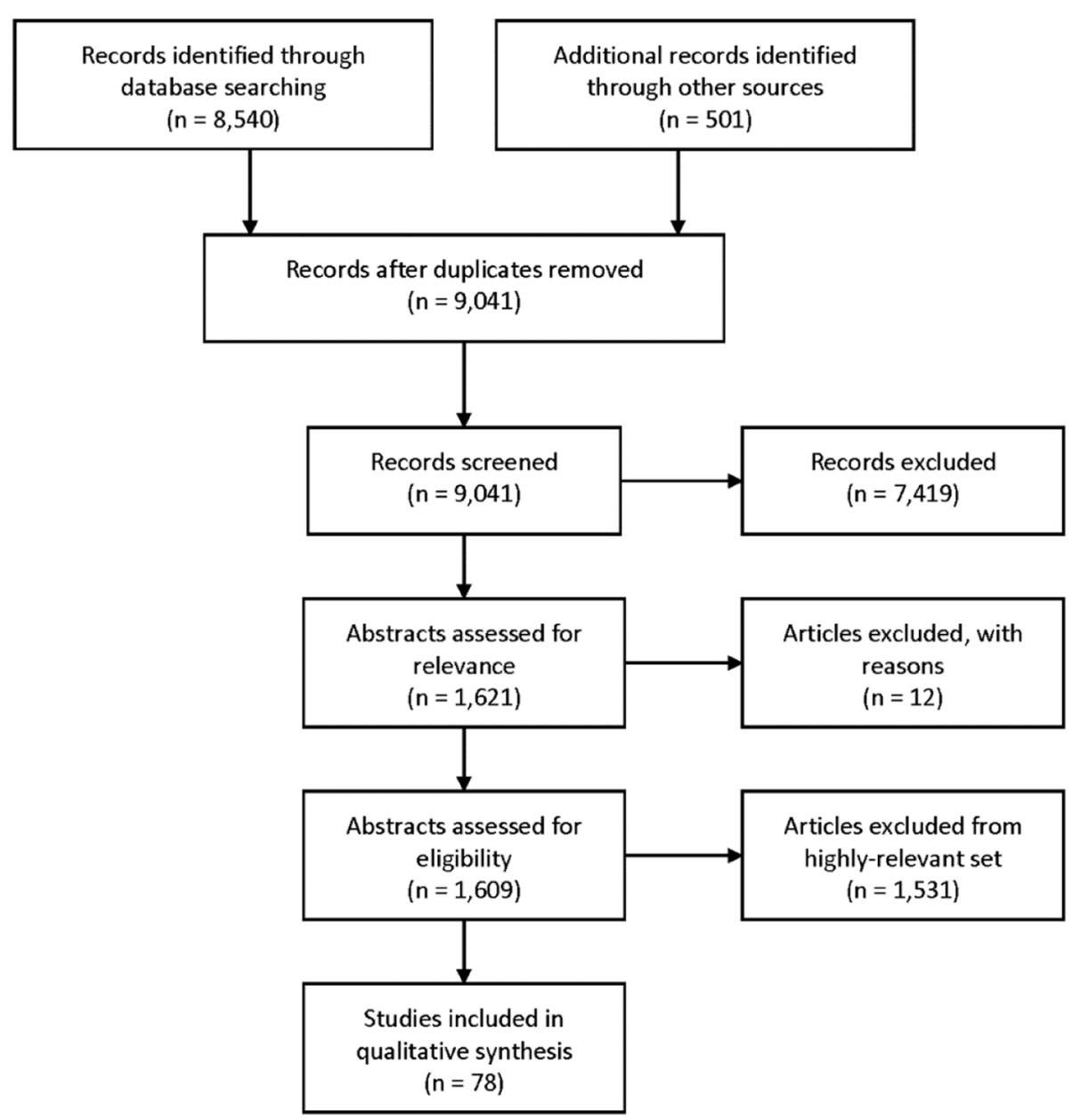

Fig. 1 Flow diagram of search and selection. The systematic review assessed 1621 articles for their degree of relevance, and included the 78 most-relevant articles in qualitative synthesis 


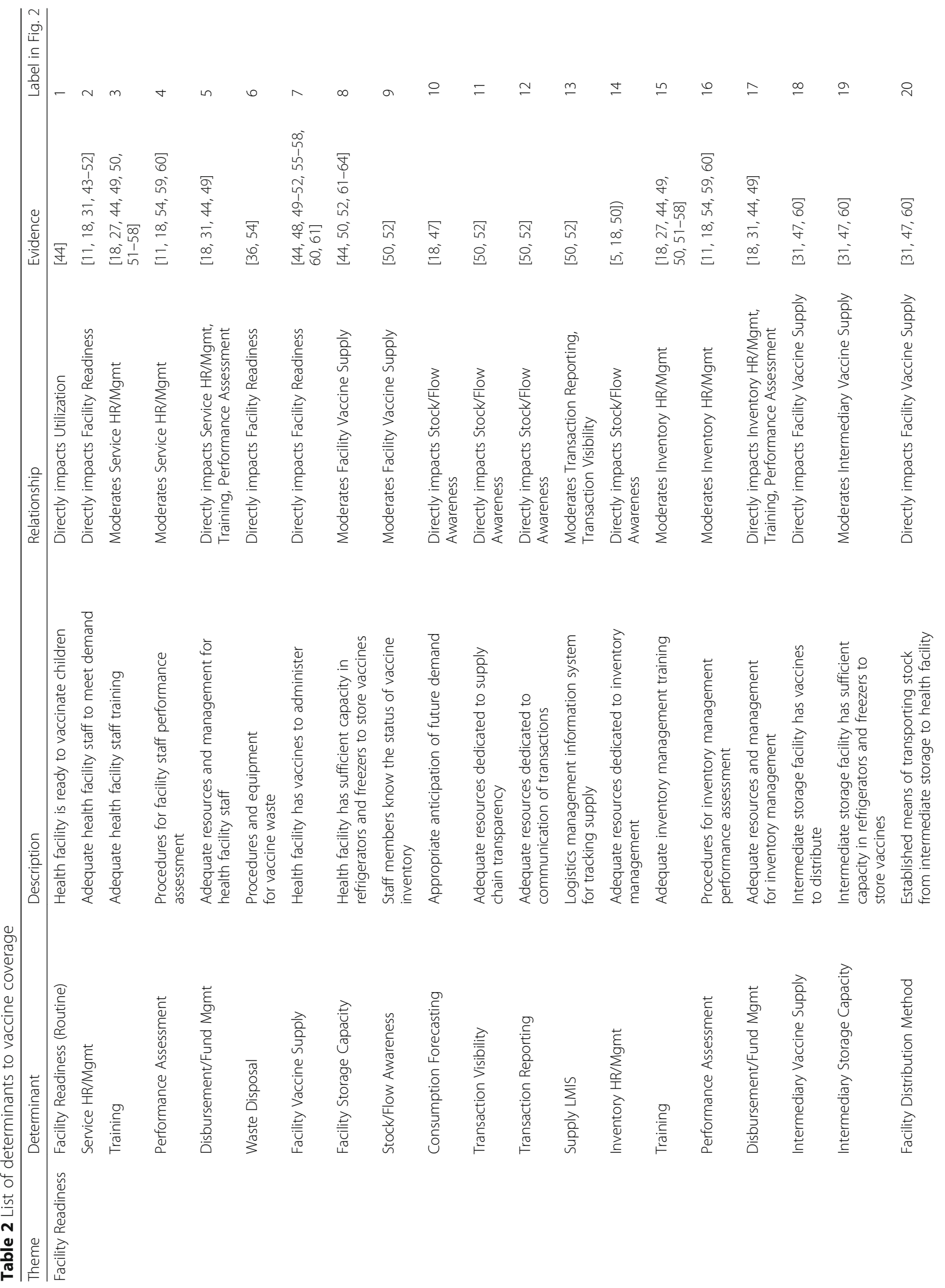




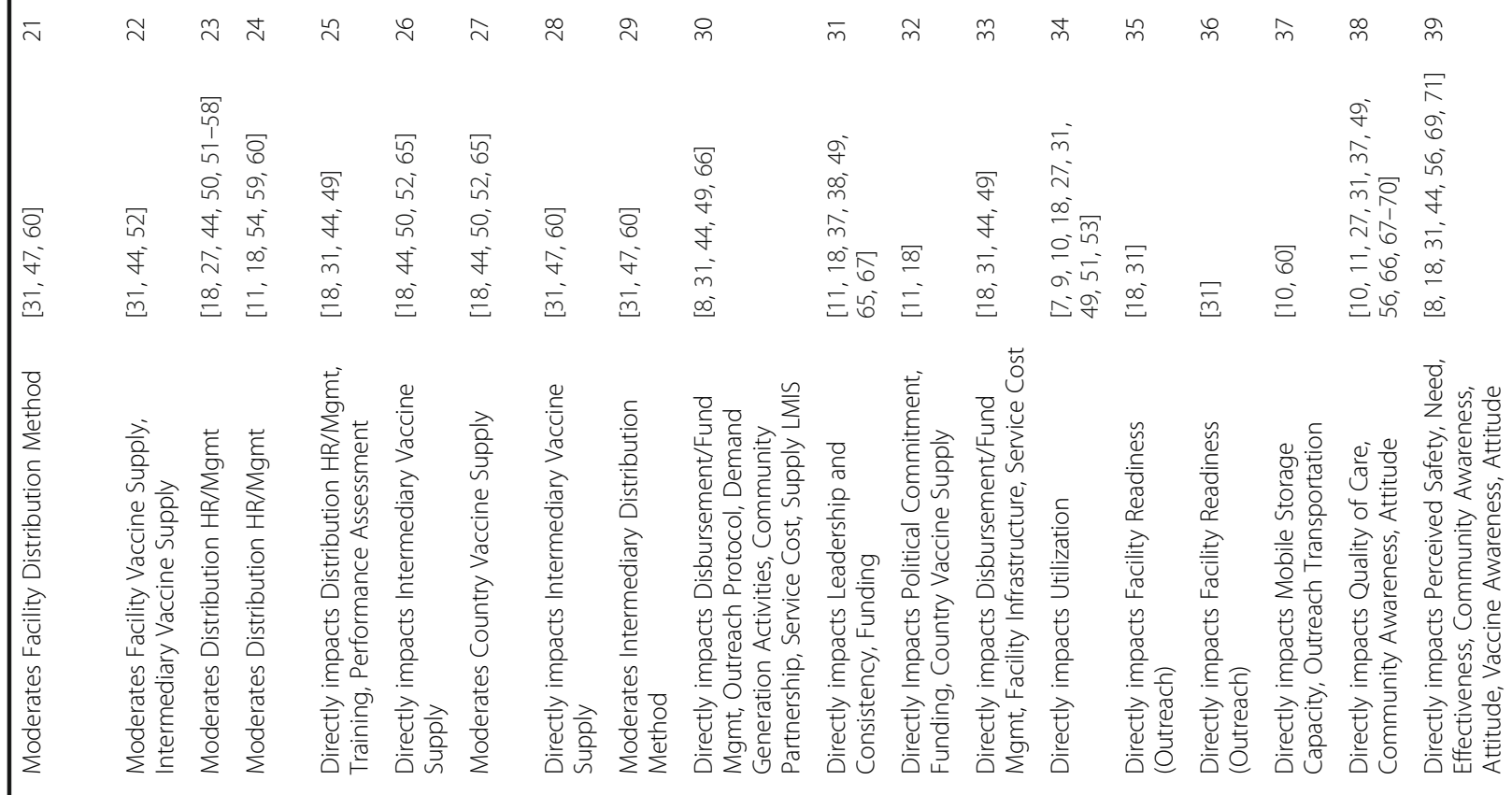

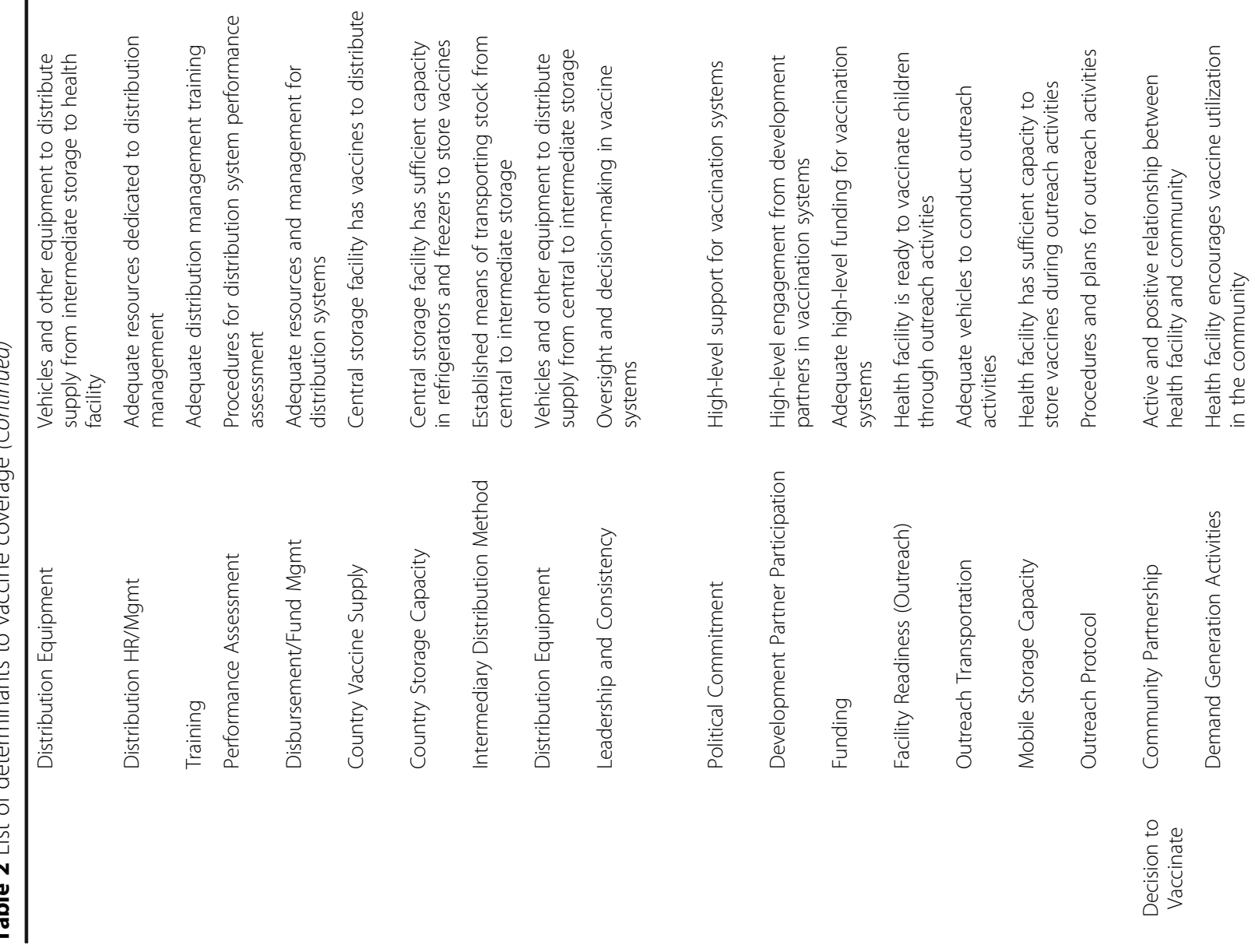




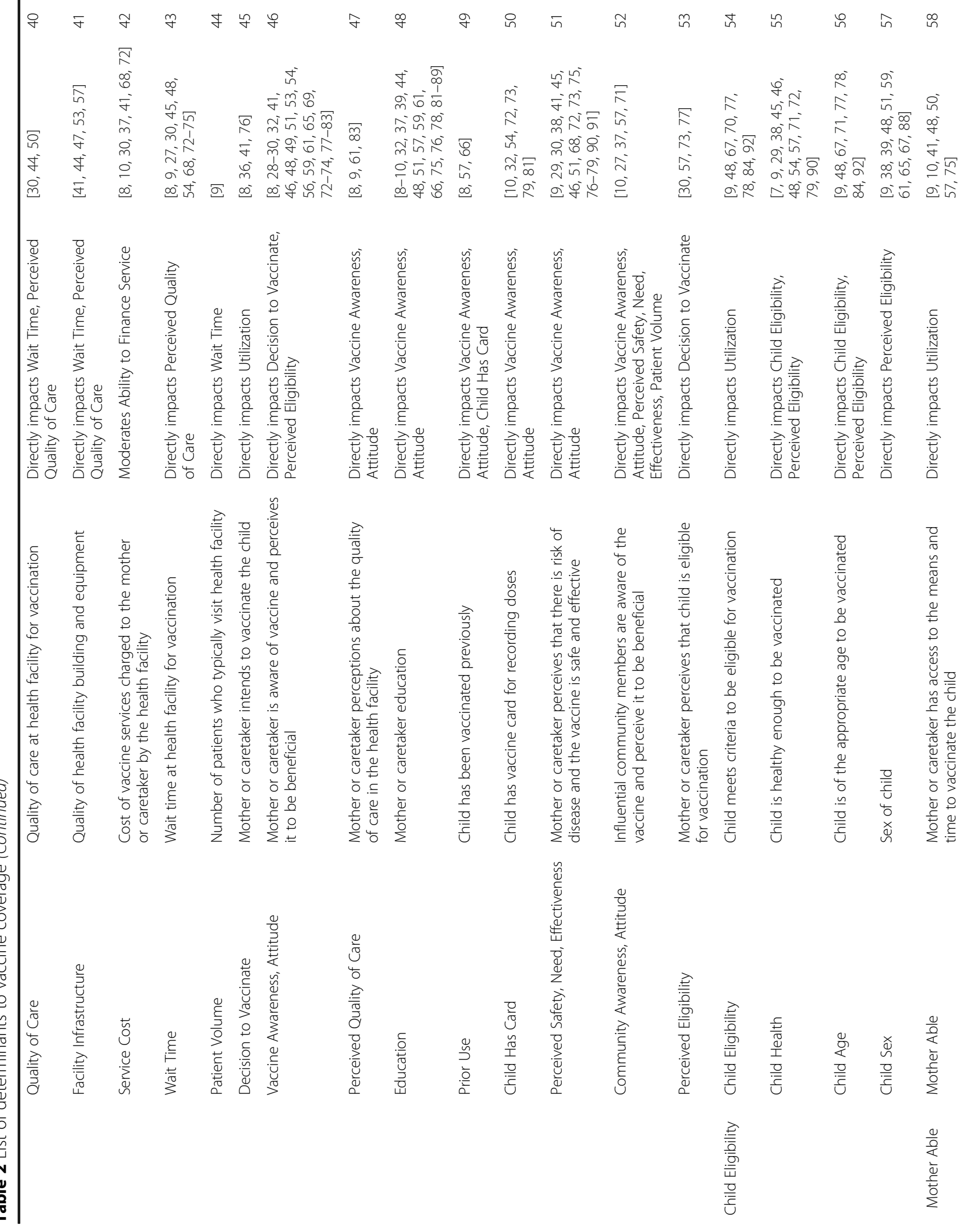


Phillips et al. BMC Health Services Research (2017) 17:681

Page 9 of 17

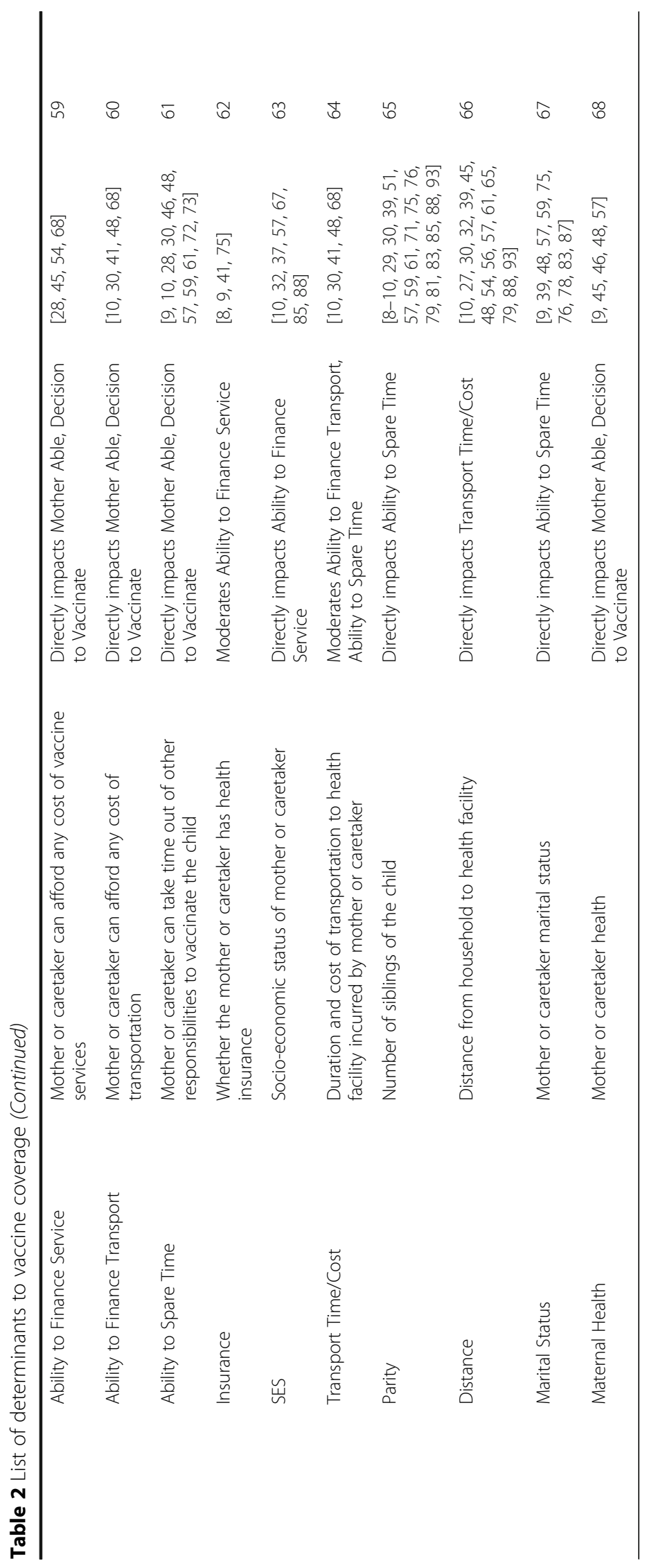




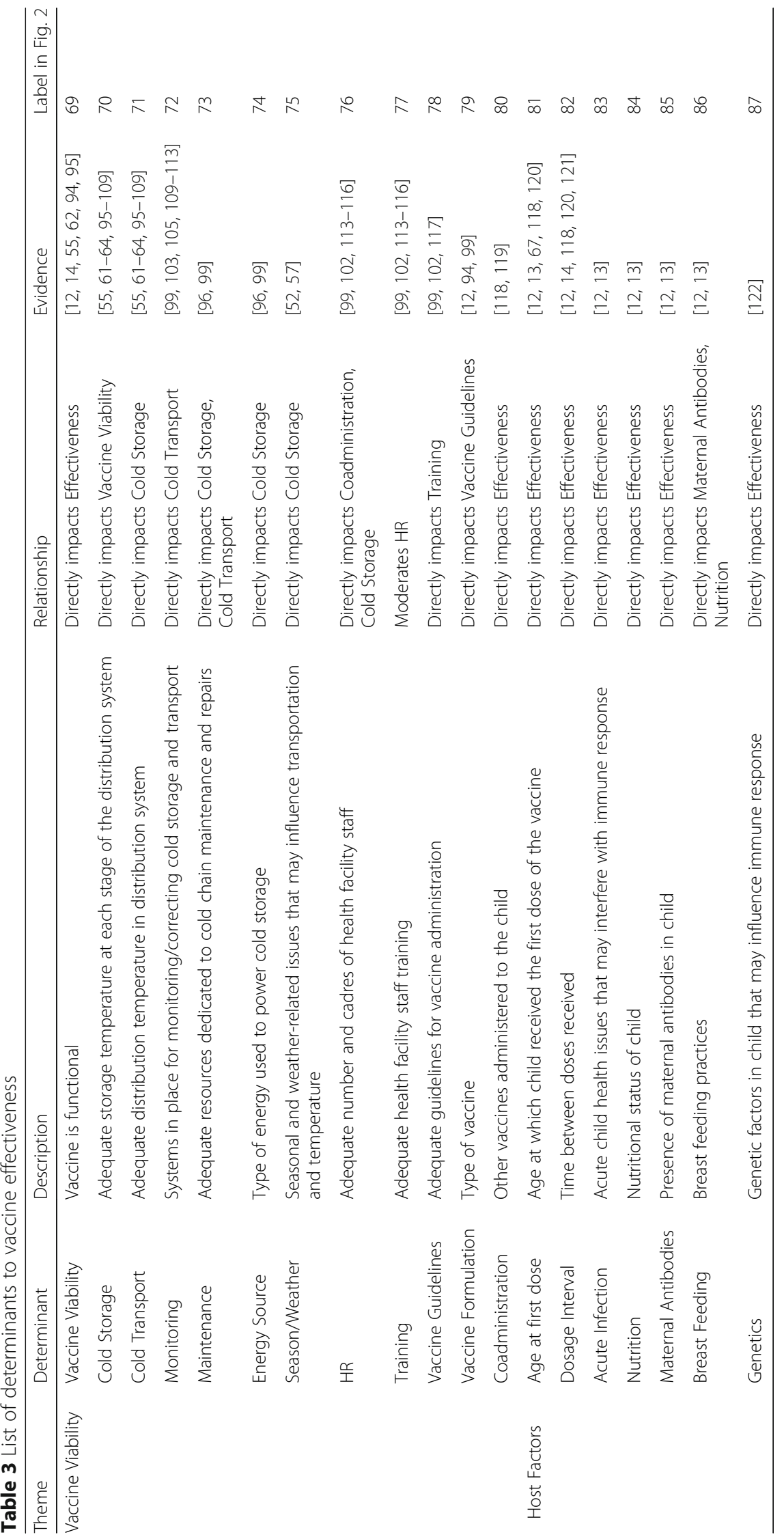




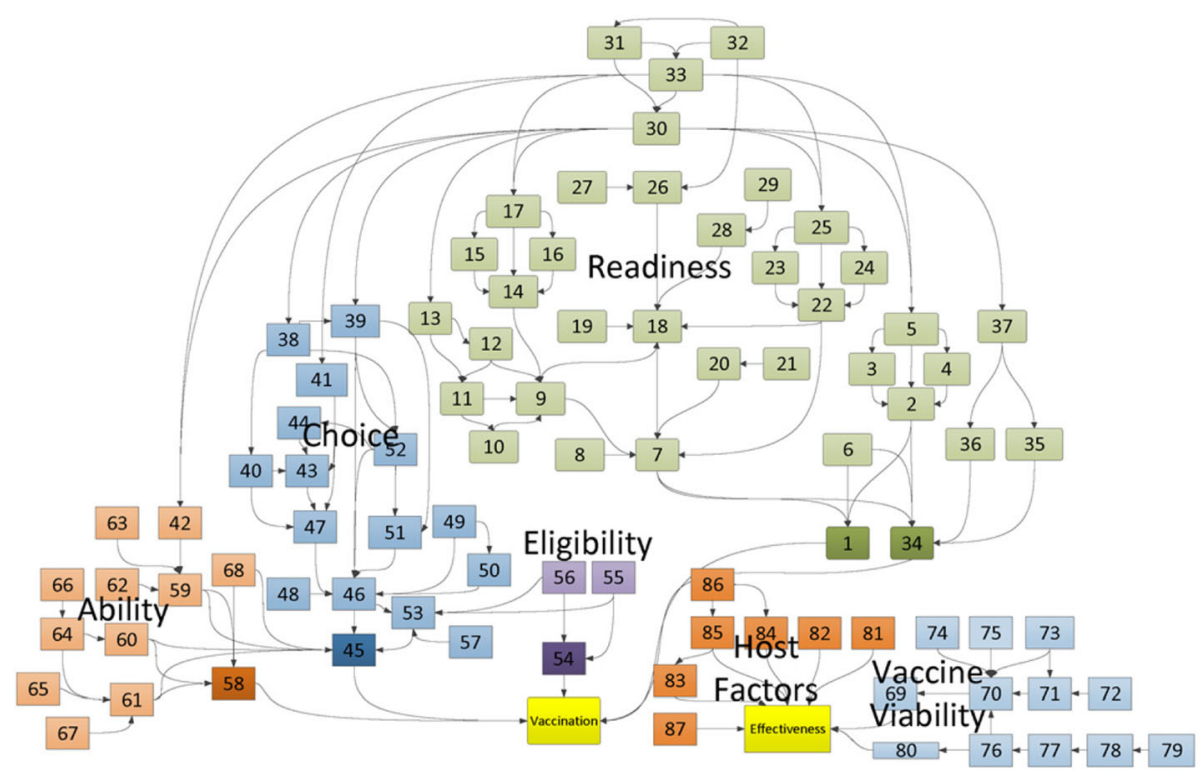

Fig. 2 Network of determinants to vaccine effective coverage. This figure displays the full picture of determinants to vaccination and immunity. For details on individual determinants, refer to Table 2 and Table 3

\section{Synthesis of results \\ Thematic analysis}

Thematic analysis was conducted concurrently with content analysis. The ways in which authors grouped together determinants were documented, and excerpts related to those themes were examined. This especially focused on the definition and justification of each theme according to the author. Authors' descriptions regarding interactions between themes were also examined. Often, authors tended to use thematic groups as a convenient way to summarize their approach, reflecting their preconceptions about a theory of determinants. Of the 78 extracted articles, 41 relied on thematic groups.

Three major thematic models (i.e. broader frameworks of themes) emerged from this analysis. One common model can be described as proximity. Authors who relied on proximity tended to group together determinants in terms of whether they were thought to directly impact vaccine coverage, or whether they were thought to impact vaccine coverage through a mediating factor. For example, Gauri and Kalenghian (2002) describe very high-level political, economic and social determinants in contrast to individual-level demand and acceptance, with accompanying description of the mechanisms of mediation [37]. Another common thematic model can be described as patient-centric. Numerous studies went into thorough detail conceptualizing the differences between determinants on the "demand side", and tended to group all other determinants as "health system factors". Chen (1986) for example provides a useful example of patient-centrism, in which a richness of information is provided about "biosocial" and "demand/utilization" factors, but health system factors are described with greater ambiguity, focusing on the high-level structure of the health system without any further detail [38]. In contrast, other models can be described as health system-centric, wherein more attention is given to factors on the "supply side", and most other determinants are classified as "demand factors". One example is Naimoli et al. (2008), who report four themes and 18 determinants relating to the health system, but only one theme with very little detail to describe all of demand [18]. Figure 3 displays the proximity model mapped to the content analysis.

Some areas of overlap emerged between themes. It was noted that the "health system factors" from patientcentric models, and the "demand factors" from health system-centric models often referred to the same thing: a more intermediate class of determinants that could be described as access or ability (both physical access and resource capacity). For example, Agot (2014) (one patientcentric study) emphasizes the health system, but describes health system factors as distance and cost incurred to the patient [39]. While these can be considered characteristics of the health system, they may usefully described as barriers between the child's caretaker and the health workers. It was also noted that studies from high-income countries tended to describe a narrower range of determinants than studies from LMICs. Among these studies, few thematic groups pertained to the health system itself, with the most focusing on knowledge and perceptions and some pertaining to logistical limitations to access $[8,29]$.

\section{Interpretive synthesis}

Interpretive synthesis was the third analysis conducted, using the information from the systematic review. 


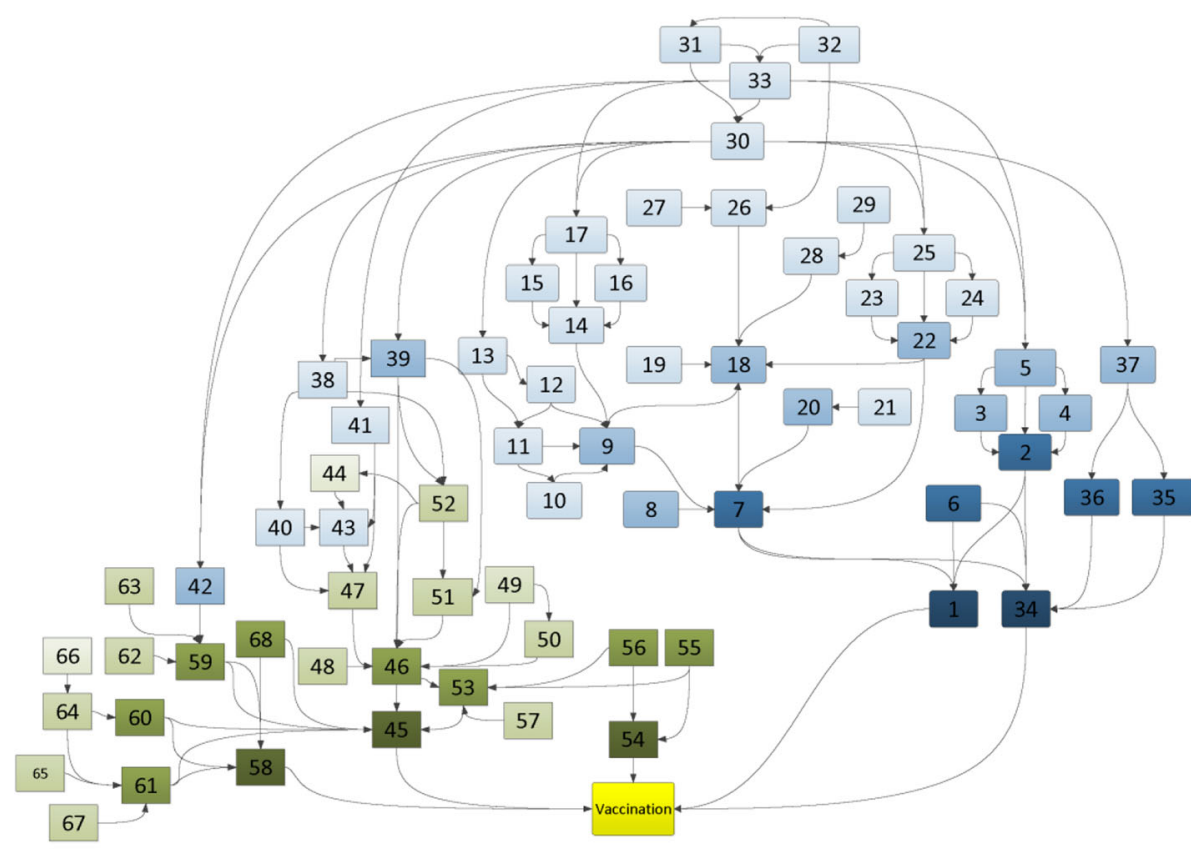

$\equiv$ Proximal

Intermediate 1

Intermediate 2

Distal

Fig. 3 Network of determinants to vaccine effective coverage. This figure displays an example of findings from Thematic Analysis. Vaccination determinants in Fig. 2 have been labeled to represent one thematic model: proximity. For details on individual determinants, refer to Table 2

Interpretive synthesis followed the approach outlined by Dixon-Woods et al. (2006), [20] with the goal of generating a succinct and testable depiction of factors leading to vaccination. This entailed further comparison of themes, as well as integration of existing conceptual frameworks.

Three existing conceptual frameworks were explored in depth. The earliest framework found in the literature was described by Rudner-Lugo (1993) [8]. This model largely builds on the Health Belief Model [40], and describes perceived cost versus benefit of vaccination as the deciding determinant of vaccine utilization. The author depicts four demand-side factors and three supplyside factors contributing to that cost-benefit assessment. The second conceptual framework was put forward by Katz et al. (2010) [41]. These authors used systematic review and previous health behavior theories to generate what they title the Vaccine Perceptions, Accountability and Adherence Model. This model places additional emphasis on "cultural and economic forces", while also recognizing the importance of barriers and "structural factors". The third framework was proposed by LaFond et al. (2014) [11]. These authors offer a substantially different framework, focusing heavily on community engagement, awareness and commitment from high-level institutions such as government and development partners.

The conceptual framework we present draws lessons, similarities and differences from each of the above frameworks. The Rudner-Lugo framework lays out a useful structure of demand and supply-side factors coming together to lead to utilization, each with distinct contributing factors. The Katz et al. framework adds extended background to demand-side factors, especially with emphasis on perception-related decision making rather than strictly economic choices. The LaFond model brings an emphasis on community-level factors which was captured by neither of the other two. Our own thematic analysis (as discussed above) identified an important third construct between supply and demand: one relating to access and barriers to access. We therefore depict a framework based around three synthetic constructs: 1 ) health facility readiness to administer vaccines, 2) community-level access 
and 3) intention (on the part of the mother or caretaker) to vaccinate the child.

General theories of health service utilization were used to describe contributors to the three primary constructs. Contributing factors for Health Facility Readiness were identified using the WHO Health System Building Blocks Framework [15]. This framework describes Supply of essential medicines and health Workforce as the most proximal components of a successful health system [15]. Contributing factors to Intent to Vaccinate were identified based on the Theory of Planned Behavior, a highly-cited behavior change model for health service utilization [36]. According to this theory, the three contributing factors to Intent are Attitudes, Perceived Norms, and Perceived Control, which is sometimes described as perceived self-efficacy. The resulting framework is depicted in Fig. 4.

The framework hypothesizes three principal determinants of vaccine utilization:

- Intent to Vaccinate - Demand for vaccines on the part of the mother that would result in vaccination in the absence of other barriers.

- Facility Readiness - Supply (by the health system) of vaccine services to adequately meet demand. Incorporates supplies (vials, syringes etc.), human resources and the consistency of their availability.

- Community Access - The ability (or inability) to successfully carry out the transaction of vaccine utilization, i.e. barriers and facilitators between Intent and Readiness.

Each principal determinant is also influenced by contributing factors, such as attitudes, norms and perceptions [36] for Intent to Vaccinate, and supply and workforce for Facility Readiness [15].

This framework represents the principal determinants in their most simplified form; as separate and distinct from one another. This was done in order to accomplish the main objective of producing a testable hypothesis, but does not preclude analysis of these constructs with correlation.

\section{Discussion}

This study identifies three principal determinants of vaccine coverage: Intent to Vaccinate, Health Facility Readiness and Community Access. We present these results as part of the most comprehensive systematic review of vaccine determinants to date including three qualitative analyses and synthesis of the information we gathered into an evidence-based conceptual framework. The key advantages of the conceptual framework are that it is designed to be exhaustive, succinct and testable.

This systematic review has a key advantages over previous reviews. First, this review includes a broader set of studies than previous reviews. For example, Rudner Lugo (1993) [8] Falagas (2008) [9] Rainey (2011) [10] and LaFond (2014) [11] each performed systematic reviews to examine factors associated with vaccine coverage, but none of the reviews cited any of the others. Second, none of these studies examine the factors which impact the effectiveness of vaccines. On the contrary, Patriarca (1991) [12], Akande (2007) [13] and Cherry (2012) [14] explore reasons behind the effectiveness of vaccines but not utilization, and only focus on a subset of determinants. Beyond these, there are hundreds of studies which consider factors relating to either utilization or effectiveness but are not exhaustive in terms of the reasons they explore.

The conceptual framework presented here has advantages over previous frameworks as well. First, it represents a synthesis of multiple existing frameworks. Our analysis draws the most useful characteristics from each of them to avoid gaps that disadvantage other frameworks. Second, it was designed to be applicable in LMICs. Among the two previous systematic reviews which offer a conceptual

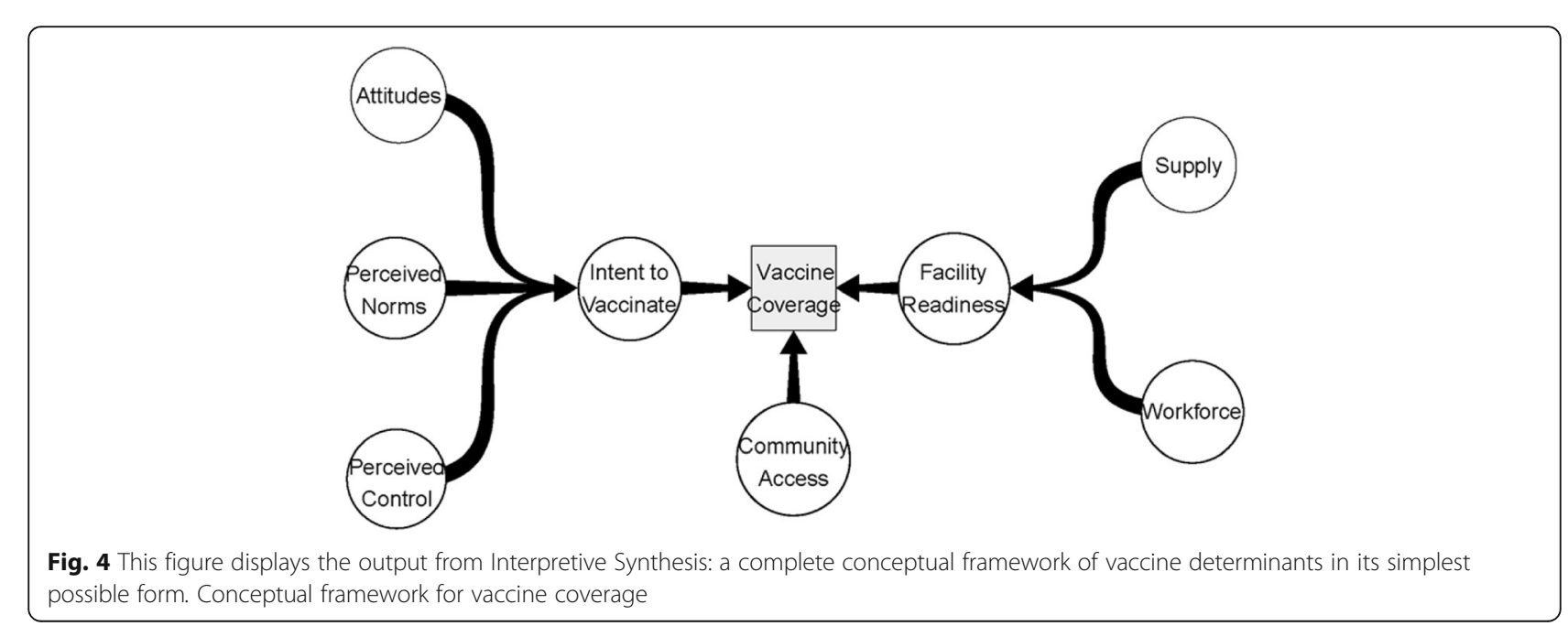


framework $[8,11]$, only one of them focuses on LMICs, and that framework focuses on only a select few determinants [11]. Third, the conceptual framework presented here integrates the Theory of Planned Behavior and the WHO Building Blocks models. Both are vetted, tested models, the former of which has quantitatively outperformed other theories in direct comparisons [42]. Finally, this framework was designed to be quantitatively testable, a characteristic that is absent in at least some other frameworks. With appropriate data, the constructs in this framework could be directly represented using latent variable analysis. Future data collection and analysis plans could take advantage of this conceptual framework to be more grounded in existing research.

In light of this study's strengths, a number of limitations remain. Although the network of determinants (Fig. 1) is intended to be comprehensive, one limitation of this study is completeness. There are four reasons why this study may not be considered complete. First, it is only complete within the context of the scientific literature. Any determinants that have been systematically overlooked by other researchers will not be present here. Second, the systematic review did not include studies of specific interventions to improve vaccine coverage, just research on determinants. Because of this, there is potential for our analyses to exclude potentially influential information. Third, it is only complete within a certain degree of proximity to utilization. One could continue to argue that each determinant has its own preceding determinants ad infinitum. While this may be true, it is clearly not the goal of this research to describe the entire spectrum of socioeconomic forces, thus only reasonably proximal determinants were described. Last, despite going to great lengths to uncover as many relevant articles as possible, it may be that some research studies were simply missed, or inaccurately assessed for relevance. Although the best practice for study completeness would have been a capture-recapture method, with a citation list of 1621 articles, we are confident that such studies are few [43]. Another potential limitation is that the entire study (web searches, review, analysis and synthesis) was conducted by a single researcher. While it would have been ideal to rely on multiple reviewers and assessment of inter-rater reliability, that was not feasible for this study.

\section{Conclusions}

This study offers important contributions to the understanding of routine childhood vaccination in low and middle income countries. One is simply the list of studies it identified (Additional file 3). We consider this to be a useful public resource in its own right. Now that a near-complete list of studies exists, future researchers can perform their own qualitative analysis and develop competing conceptual frameworks with greater ease. Because of the results of the content analysis (Tables 1 and 2), researcher can easily look up other studies that discuss any determinant in particular. This study contributes conceptual framework of determinants of effective coverage of childhood vaccines that represents a synthesis of multiple existing frameworks, is applicable in low and middle-income countries, and is quantitatively testable. Future quantitative researchers can use this study to identify appropriate indicators to analyze and to define their theoretical model. By bringing together the collective evidence on the drivers of immunization, this review lends itself to better research in the future, further understanding of determinants, and greater progress against vaccine preventable diseases around the world.

\section{Additional files}

Additional file 1: Protocol. (DOCX $21 \mathrm{~kb}$ )

Additional file 2: List of Potential Search Terms, Searches Conducted and Summary of Results. (XLSX $20 \mathrm{~kb}$ )

Additional file 3: Complete List of Citations, Sorted by Relevance. (XLSX $212 \mathrm{~kb})$

\section{Abbreviations}

DALY: Disability-adjusted life year; DTP3: Diphtheria, tetanus, pertussis vaccine (3 doses); LMICs: Low and middle-income countries; LOA: Lines-of-argument synthesis; RTA: Reciprocal translational analysis; WHO: World Health Organization

\section{Acknowledgements \\ Not applicable}

\section{Funding}

This research was supported by Gavi, the Vaccine Alliance as part of the Gavi Full Country Evaluation Study. The funder had no involvement in study design, data collection, analysis, interpretation of data, writing of this manuscript or decision to submit for publication.

\section{Availability of data and materials}

The complete list of studies documented in this research is listed in Additional file 3. This includes citation information, and meta-data data extracted from selected studies.

\section{Authors' contributions}

All authors contributed equally to the conception of the study. DEP performed the systematic review, carried out all analyses and drafted the manuscript. JLD, JS and SSL provided analytical guidance and direction of the project. All authors read and approved the final manuscript.

Ethics approval and consent to participate

Not applicable

Consent for publication

Not applicable

Competing interests

The authors declare that they have no competing interests.

\section{Publisher's Note}

Springer Nature remains neutral with regard to jurisdictional claims in published maps and institutional affiliations.

\section{Author details}

${ }^{1}$ Institute for Health Metrics and Evaluation, University of Washington, Seattle, USA. ${ }^{2}$ PATH, Seattle, USA. 
Received: 24 April 2017 Accepted: 18 September 2017 Published online: 26 September 2017

\section{References}

1. World Health Organization, UNICEF, World Bank. State of the world's vaccines and immunization [Internet]. 3rd ed. Geneva, Switzerland: WHO; 2009. Available from: http://apps.who.int/iris/bitstream/10665/63027/1/ WHO_GPV_96.04.pdf

2. Jha P, Chaloupka FJ, Moore J, Gajalakshmi V, Gupta PC, Peck R, et al. Disease control priorities in developing countries. 2nd ed. New York: Oxford University Press; 2006

3. Abubakar II, Tillmann T, Banerjee A. Global, regional, and national age-sex specific all-cause and cause-specific mortality for 240 causes of death, 1990-2013: a systematic analysis for the global burden of disease study 2013. Lancet. 2015;385(9963):117-71.

4. Harris JB, Gacic-Dobo M, Eggers R, Brown DW, Sodha SV, Control C. For D, et al. global routine vaccination coverage, 2013. MMWR Morb Mortal Wkly Rep. 2014;63(46):1055-8.

5. Restrepo-Méndez MC, Barros AJ, Wong KL, Johnson HL, Pariyo G, França GV et al. Inequalities in full immunization coverage: trends in low-and middleincome countries. Sierra. 2016;3(1.3):0-005.

6. Centers for Disease Control and Prevention. CDC Health Information for International Travel 2014: The Yellow Book. New York: Oxford University Press: 2013.

7. Cutts FT, Smith PG, Colombo S, Mann G, Ascherio A, Soares AC. Field evaluation of measles vaccine efficacy in Mozambique. Am J Epidemiol. 1990;131(2):349-55.

8. Rudner Lugo N. The Relationships among Service Delivery Factors, Community Characteristics, and Immunization Completion by Two-Year-Old Children Using County Health Departments [Internet]. 1993 [cited 2017 Jun 13]. Available from: http://elibrary.ru/item.asp?id=5765487

9. Falagas ME, Zarkadoulia E. Factors associated with suboptimal compliance to vaccinations in children in developed countries: a systematic review. Curr Med Res Opin. 2008;24(6):1719-41.

10. Rainey JJ, Watkins M, Ryman TK, Sandhu P, Bo A, Banerjee K. Reasons related to non-vaccination and under-vaccination of children in low and middle income countries: findings from a systematic review of the published literature, 1999-2009. Vaccine. 2011;29(46):8215-21.

11. LaFond A, Kanagat N, Steinglass R, Fields R, Sequeira J, Mookherji S. Driver of routine immunization coverage improvement in Africa: findings from district-level case studies. Health Policy Plan. 2014;298-308. czu011.

12. Patriarca PA, Wright PF, John TJ. Factors affecting the immunogenicity of oral poliovirus vaccine in developing countries: review. Rev Infect Dis. 1991:13(5):926-39.

13. Akande TM. A review of measles vaccine failure in developing countries. Niger Med Pract. 2007;52(5-6):112-6.

14. Cherry JD. Why do pertussis vaccines fail? Pediatrics. 2012;129(5):968-70.

15. World Health Organization. Monitoring the building blocks of health systems: a handbook of indicators and their measurement strategies [Internet]. [cited. Jun 13. 2017; Available from: http://www.who.int/ healthinfo/systems/monitoring/en/

16. World Health Organization. Principles and considerations for adding a vaccine to a national immunization programme: from decision to implementation and monitoring. [Internet]. World Health Organization; 2014. Available from: https:// www.cabdirect.org/cabdirect/abstract/20153178719

17. Hyde TB, Dentz H, Wang SA, Burchett HE, Mounier-Jack S, Mantel CF, et al. The impact of new vaccine introduction on immunization and health systems: a review of the published literature. Vaccine. 2012;30(45):6347-58

18. Naimoli JF, Challa S, Schneidman M, Kostermans K. Toward a grounded theory of why some immunization programmes in sub-Saharan Africa are more successful than others: a descriptive and exploratory assessment in six countries. Health Policy Plan. 2008;23(6):379-89.

19. Dixon-Woods M, Agarwal S, Jones D, Young B, Sutton A. Synthesising qualitative and quantitative evidence: a review of possible methods. J Health Serv Res Policy. 2005;10(1):45-53.

20. Dixon-Woods M, Cavers D, Agarwal S, Annandale E, Arthur A, Harvey J, et al. Conducting a critical interpretive synthesis of the literature on access to healthcare by vulnerable groups. BMC Med Res Methodol. 2006;6(1):35.

21. Health Systems Evidence [Internet]. Available from: https://www. healthsystemsevidence.org/.
22. Cochrane Library [Internet]. [cited 2017 Jun 13]. Available from: http://www. cochranelibrary.com/

23. Systematic Reviews [Internet]. [cited 2017 Jun 13]. Available from: https://systematicreviewsjournal.biomedcentral.com/

24. Agency for Healthcare Research \& Quality [Internet]. [cited 2017 Jul 24] Available from: https://www.ahrq.gov/

25. University of York. Centre for Reviews and Dissemination [Internet]. [cited 2017 Jun 13]. Available from: https://www.york.ac.uk/crd/

26. EPPI-Centre [Internet]. [cited 2017 Jun 13]. Available from: https://eppi.ioe.ac. uk/cms/

27. Ryman TK, Dietz V, Cairns KL. Too little but not too late: results of a literature review to improve routine immunization programs in developing countries. BMC Health Serv Res. 2008;8(1):134.

28. Johri M, Pérez MC, Arsenault C, Sharma JK, Pai NP, Pahwa S, et al. Strategies to increase the demand for childhood vaccination in low-and middleincome countries: a systematic review and meta-analysis. Bull World Health Organ. 2015;93(5):339-46.

29. Tickner S, Leman PJ, Woodcock A. Factors underlying suboptimal childhood immunisation. Vaccine. 2006;24(49):7030-6.

30. Mills E, Jadad AR, Ross C, Wilson K. Systematic review of qualitative studies exploring parental beliefs and attitudes toward childhood vaccination identifies common barriers to vaccination. J Clin Epidemiol. 2005:58(11):1081-8.

31. Haddad S, Bicaba A, Feletto M, Taminy E, Kabore M, Ouédraogo B, et al. System-level determinants of immunization coverage disparities among health districts in Burkina Faso: a multiple case study. BMC Int Health Hum Rights. 2009;9(1):S15

32. Bbaale E. Factors influencing childhood immunization in Uganda. 2013; Available from: https://tspace.library.utoronto.ca/handle/1807/50572

33. Mays N, Roberts E, Popay J. Synthesising research evidence. In: Studying the organisation and delivery of health services: research methods. London, UK: Routledge; 2001. p. 188-220.

34. Barnett-Page $E$, Thomas J. Methods for the synthesis of qualitative research: a critical review. BMC Med Res Methodol. 2009;9(1):59.

35. Noblit GW, Hare RD. Meta-ethnography: Synthesizing qualitative studies, vol Vol. 11. USA: Sage; 1988

36. Ajzen I. The theory of planned behavior. Organ Behav Hum Decis Process 1991;50(2):179-211.

37. Gauri V, Khaleghian P. Immunization in developing countries: its political and organizational determinants. World Dev. 2002;30(12):2109-32.

38. Chen L. Primary health care in developing countries: overcoming operational, technical, and social barriers. Lancet. 1986;328(8518):1260-5.

39. Agot GN. The determinants of measles vaccination in Kenya [internet] University of Nairobi; 2014. Available from: http://erepository.uonbi.ac.ke/ handle/11295/76659

40. Rosenstock IM. Why people use health services. Milbank Q. 2005;83(4):94-127.

41. Katz IT, Ware NC, Gray G, Haberer JE, Mellins CA, Bangsberg DR. Scaling up human papillomavirus vaccination: a conceptual framework of vaccine adherence. Sex Health. 2010:7(3):279-86.

42. Gerend MA, Shepherd JE. Predicting human papillomavirus vaccine uptake in young adult women: comparing the health belief model and theory of planned behavior. Ann Behav Med. 2012;44(2):171-80.

43. Kastner $\mathrm{M}$, et al. The capture-mark-recapture technique can be used as a stopping rule when searching in systematic reviews. J Clin Epidemiol. 2009:62(2):149-157.

44. Gavi Full-Country Evaluation Team. Process evaluation of pneumococcal vaccine introduction in Mozambique, Uganda, and Zambia [internet]. Gavi alliance; 2014. Available from: http://www.gavi.org/Library/GAVI-documents/ Evaluations/Process-evaluation-report-of-Pneumococcal-VaccineIntroduction-in-Mozambique,-Uganda-and-Zambia/

45. Abdulraheem IS, Onajole AT, Jimoh AAG, Oladipo AR. Reasons for incomplete vaccination and factors for missed opportunities among rural Nigerian children. J Public Health Epidemiol. 2011;3(4):194-203.

46. Tagbo BN, Eke CB, Omotowo BI, Onwuasigwe CN, Onyeka EB, Mildred UO, et al. Vaccination coverage and its determinants in children aged 11-23 months in an Urban District of Nigeria. World J Vaccines. 2014;4(04):175.

47. Reach V. Starting at the last mile: rethinking medical supply chains in lowincome countries [internet]. Seattle, USA: Village Reach; 2012. Available from: http://www.villagereach.org/wp-content/uploads/2012/03/02272012. Starting-at-the-Last-Mile-Whitepaper.pdf 
48. Jani JV, De Schacht C, Jani IV, Bjune G. Risk factors for incomplete vaccination and missed opportunity for immunization in rural Mozambique. BMC Public Health. 2008;8(1):161.

49. Norwegian Agency for Development Cooperation. Alleviating System Wide Barriers to Immunization: Issues and conclusions from the Second GAVI Consultation with Country Representatives and Global Partners [Internet]. Geneva, Switzerland: GAVI Alliance; 2004. Available from: http://www.gavi. org/library/publications/other-publishers/other/alleviating-system-widebarriers-to-immunization/

50. Dowling P. Healthcare Supply Chains in Developing Countries: Situational Analysis. Arlingt Va USAID Deliv Proj [Internet]. 2011; Available from: https:// peoplethatdeliver.org/ptd/sites/default/files/resource_contents_files/ Healthcare\%20Supply\%20Chains\%20-\%20Situation\%20Analysis\%20EN.pdf

51. Fatiregun AA, Okoro AO. Maternal determinants of complete child immunization among children aged 12-23 months in a southern district of Nigeria. Vaccine. 2012;30(4):730-6.

52. Ecumenical Pharmaceutical Network. Effective pharmaceutical supply chains: On the road in low income countries [Internet]. EPN; 2011. Available from: http://apps.who.int/medicinedocs/documents/s19965en/s19965en.pdf.

53. Oya-Ita A, Nwachukwu CE, Oringanje C, Meremikwu MM. Interventions for improving coverage of child immunization in low-income and middleincome countries. Cochrane Database Syst Rev. 2009;(7):DOl: 10.1002/ 14651858.CD008145.pub2.

54. Omutanyi RM, Mwanthi MA. Determinants of immunisation coverage in Butere-Mumias district, Kenya. East Afr Med J. 2005;82(10):501-5.

55. Cheyne J. Vaccine delivery management. Rev Infect Dis. 1989; 11(Supplement 3):S617-22.

56. DeRoeck D, Levin A. Review of financing of immunization programs in developing and transitional countries. 1998 [cited 2017 Jun 13]; Available from: http://www.popline.org/node/532199

57. Kamanda BC. Immunization coverage and factors associated with failure to complete childhood immunization in Kawempe division, Uganda [internet] University of the Western Cape; 2010. Available from: http://etd.uwc.ac.za/ xmlui/handle/11394/2595

58. Uddin MJ, Larson CP, Oliveras E, Khan Al, Quaiyum MMA, Chandra SN. Child immunization coverage in rural hard-to-reach Haor areas of Bangladesh: possible alternative strategies. Asia Pac J Public Health. 2009;21(1):8-18.

59. Kawakatsu $Y$, Honda S. Individual-, family-and community-level determinants of full vaccination coverage among children aged 12-23 months in western Kenya. Vaccine. 2012;30(52):7588-93.

60. Subramanyam K. Vaccine distribution: an operations research study. Rev Infect Dis. 1989;11(Supplement 3):S623-S628.

61. Calhoun LM, van Eijk AM, Lindblade KA, Odhiambo FO, Wilson ML, Winterbauer $\mathrm{E}$, et al. Determinants and coverage of vaccination in children in western Kenya from a 2003 cross-sectional survey. Am J Trop Med Hyg. 2014;90(2):234-41.

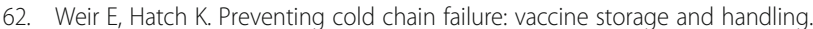
Can Med Assoc J. 2004;171(9):1050-0.

63. Haidari LA, Connor DL, Wateska AR, Brown ST, Mueller LE, Norman BA, et al. Augmenting transport versus increasing cold storage to improve vaccine supply chains. PLoS One. 2013;8(5):e64303.

64. Matthias DM, Robertson J, Garrison MM, Newland S, Nelson C. Freezing temperatures in the vaccine cold chain: a systematic literature review. Vaccine. 2007;25(20):3980-6.

65. Tsu VD. Overcoming barriers and ensuring access to HPV vaccines in lowincome countries. Am J Law Med. 2009;35(2-3):401-13.

66. Sia D, Kobiané JF, Sondo BK, Fournier P. Individual and environmental characteristics associated with immunization of children in rural areas in Burkina Faso: a multi-level analysis. Sante Montrouge Fr. 2006;17(4):201-6.

67. Ataguba JE, Ojo KO, Ichoku HE. Explaining socio-economic inequalities in immunization coverage in Nigeria. Health Policy Plan. 2016;31(9):1212-24.

68. Burns IT, Zimmerman RK. Immunization barriers and solutions. J Fam Pract. 2005;54(1):S58-8.

69. Shea B, Andersson N, Henry D. Increasing the demand for childhood vaccination in developing countries: a systematic review. BMC Int Health Hum Rights. 2009;9(1):S5.

70. Brugha RF, Kevany JP. Maximizing immunization coverage through home visits: a controlled trial in an urban area of Ghana. Bull World Health Organ. 1996;74(5):517.

71. Ruair BRUGHA, Kevany J. Immunization determinants in the eastern region of Ghana. Health Policy Plan. 1995;10(3):312-8.
72. Uddin M, Larson CP, Oliveras E, Khan Al, Quaiyum MA, Saha NC, et al. Effectiveness of combined strategies to improve low coverage of child immunization in urban slums of Bangladesh [Internet]. International Centre for Diarrhoeal Diseases Research Bangladesh: Dhaka; 2008. Available from: http:// dspace.icddrb.org/jspui/bitstream/123456789/3358/1/ICDDRBWorkingpaper169-UddinMJ.pdf

73. Perry H, Nurani S, Quaiyum MA, Jinnah SA, Sharma A, others. Barriers to immunization among women and children living in slums of Zone 3 of Dhaka city, Bangladesh: a qualitative assessment [Internet]. International centre for diarrhoeal disease research (ICDDR, B); 2007. Available from: https://www.researchgate.net/profile/Anjali_Sharma14/publication/ 237579070_Barriers_to_Immunization_among_Women_and_Children_ Living_in_Slums_of_Zone_3_of_Dhaka_City_Bangladesh_A_Qualitative_ Assessment/links/555ef98108ae8c0cab2c95b1.pdf

74. Cutts FT, Diallo S, Zell ER, Rhodes P. Determinants of vaccination in an urban population in Conakry. Guinea Int J Epidemiol. 1991;20(4):1099-106.

75. Strobino D, Keane V, Holt E, Hughart N, Guyer B. Parental attitudes do not explain underimmunization. Pediatrics. 1996;98(6):1076-83.

76. Bosch-Capblanch X, Banerjee K, Burton A. Unvaccinated children in years of increasing coverage: how many and who are they? Evidence from 96 lowand middle-income countries. Tropical Med Int Health. 2012;17(6):697-710.

77. LaMontagne DS, Barge S, Thi Le N, Mugisha E, Penny ME, Gandhi S, et al. Human papillomavirus vaccine delivery strategies that achieved high coverage in low-and middle-income countries. Bull World Health Organ. 2011;89(11):821-30.

78. Odusanya OO, Alufohai EF, Meurice FP, Ahonkhai VI. Determinants of vaccination coverage in rural Nigeria. BMC Public Health. 2008;8(1):381.

79. Cutts FT, Rodrigues LC, Colombo S, Bennett S. Evaluation of factors influencing vaccine uptake in Mozambique. Int J Epidemiol. 1989;18(2):427-33.

80. Khan A, Quaiyum MA, Gazi R, Uddin J, Ahmed F, Islam M, et al. Programmatic and non-programmatic determinants of low immunization coverage in Bangladesh. In: Presentation made at Forum. 2005.

81. Opollo M-S, Makumbi F, Mukanga D, Namusisi O, Ayebazibwe N, Tweheyo R. Factors associated with DPT 1-3 vaccine dropout in Kabarole district, western Uganda. Int J Infect Dis. 2010;14:e453-4.

82. Kamau N, Esamai FO. Determinants of immunization coverage among children in Mathare Valley. Nairobi East Afr Med J. 2001;78(11):590-4.

83. Maina LC, Karanja S, Kombich J. Immunization coverage and its determinants among children aged 12-23 months in a peri-urban area of Kenya. Pan Afr Med J. 2013;14(1)

84. Matthews Z, Diamond I. Child immunisation in Ghana: the effects of family, location and social disparity. J Biosoc Sci. 1997;29(03):327-43.

85. Schoeps A, Ouedraogo N, Kagone M, Sie A, Müller O, Becher H. Sociodemographic determinants of timely adherence to BCG, Penta3, measles, and complete vaccination schedule in Burkina Faso. Vaccine. 2013;32(1):96-102.

86. Gonçalves A, Ferrinho P, Aguiar P. Factors associated with vaccine status and health services consultation of children from a rural area of Guinea Bissau. Acta Medica Port. 2001;14(3):331-5.

87. Sackou KJ, Oga AS, Desquith AA, Houenou Y, Kouadio KL. Complete immunization coverage and reasons for non-vaccination in a periurban area of Abidjan. Bull Soc Pathol Exot. 2012;105(4):284-90.

88. de Waroux OLP, Schellenberg JRA, Manzi F, Mrisho M, Shirima K, Mshinda H, et al. Timeliness and completeness of vaccination and risk factors for low and late vaccine uptake in young children living in rural southern Tanzania. Int Health. 2013;5(2):139-47.

89. Mohammad M. Determinants of the utilization of the tetanus toxoid (TT) vaccination coverage in Bangladesh: evidence from a Bangladesh demographic health survey 2004. Internet J Health. 2008;8

90. Alfredsson R, Svensson E, Trollfors B, Borres MP. Why do parents hesitate to vaccinate their children against measles, mumps and rubella? Acta Paediatr. 2004;93(9):1232-7.

91. Laval B, Fascia P, Gocko X, Feuillet J, Lucht F. Determinants of vaccination coverage for children and teenagers. Médecine Mal Infect. 2011;41(7):359-63.

92. Ayebazibwe N. Immunization coverage and risk factors for high dropout in Rakai district. 2009; Available from: http://dspace.mak.ac.ug/handle/10570/1174

93. du Loû AD, Pison G. Barriers to universal child immunization in rural Senegal 5 years after the accelerated expanded Programme on immunization. Bull World Health Organ. 1994;72(5):751.

94. Milstien JB, Gibson JJ. Quality control of BCG vaccine by WHO: a review of factors that may influence vaccine effectiveness and safety. Bull World Health Organ. 1990;68(1):93. 
95. Kimati VP, Loretu K, Munube GMR, Kimboi F. Others. The problem of measles virus response with reference to vaccine viability, age, protein energy malnutrition and malaria in the tropics. J Trop Pediatr. 1981;27(4):205-9.

96. Rogers B, Dennison K, Adepoju N, Dowd S, Uedoi K. Vaccine cold chain: part 1. Proper handling and storage of vaccine. AAOHN J. 2010;58(8):337-46.

97. Khare S, Dutta M, Lal B, Kumari S. Quality control of cold chain system potency testing of oral polio vaccine. For Comm Bull. 1988;5:9-13.

98. Briggs H, llett S. Weak link in vaccine cold chain. BMJ. 1993;306(6877):557.

99. Centers for Disease Control and Prevention. Guidelines for maintaining and managing the vaccine cold chain. MMWR Morb Mortal Wkly Rep. 2003; 52(42):1023.

100. Wang D-Y, Yang R-I, Yang Y-C, Yeh S-Y, Chen T-L, Cheng H-F, et al. The relationship between the cold chain system and vaccine potency in Taiwan:(l) Live measles vaccine and MMR vaccine. J Food Drug Anal. 1999;7(3):233-42.

101. Zipursky S, Boualam L, Cheikh DO, Fournier-Caruana J, Hamid D, Janssen M, et al. Assessing the potency of oral polio vaccine kept outside of the cold chain during a national immunization campaign in Chad. Vaccine. 2011; 29(34):5652-6

102. Organization WH, others. Safe vaccine handling, cold chain and immunizations: A manual for the newly independent states [Fact sheet]. 1998.

103. Oyefolu AO, Nwaeke AC, Audu RA, Akinyemi KO, Salu OB, Muller CP, et al. Evaluation of measles vaccine cold chain in Lagos state. Nigeria Afr J Clin Exp Microbiol. 2007;8(1):1-7.

104. Wang D-Y, Yang R-I, Yang Y-C, Yeh S-Y, Chen T-L, Cheng H-F, et al. The relationship between the cold chain system and vaccine potency in Taiwan: (II) Oral polio vaccine. J Food Drug Anal. 2000;8(1):17-23.

105. Deshpande JM, Rao VK, Nadkarni SS, Bhatia JP, Rodrigues JJ. An evaluation of cold chain in Maharashtra \& Karnataka states by potency testing of field samples of oral poliovirus vaccine. Indian J Med Res. 1995;102:60-5.

106. Pickering LK, Wallace G, Rodewald L. Too hot, too cold: issues with vaccine storage. Pediatrics. 2006;118(4):1738-9.

107. Gold MS, Kemp AE, Osbourne M. Counting the cost of disrupting the vaccine cold chain. Med J Aust. 1998;168(9):471-2.

108. Thakker $Y$, Woods S. Storage of vaccines in the community: weak link in the cold chain? BMJ. 1992;304(6829):756-8.

109. Camacho-Amor ML, Valdespino-Gomez JL, Ayala-Gonzalez M, Diaz-Ortega $J \mathrm{~L}$, Gonzalez-Velazquez MS, Morales-Romo A, et al. Evaluation of the cold chain and follow-up of the potency of the antimeasles vaccine in the field. Bol Med Hosp Infant Mex. 1990;47(7):506-11.

110. Samant Y, Lanjewar H, Parker D, Block L, Tomar GS, Stein B. Evaluation of the cold-chain for oral polio vaccine in a rural district of India. Public Health Rep. 2007;122(1):112-21.

111. World Health Organization. Study protocol for temperature monitoring in the vaccine cold chain (WHO document WHO/IVB/05.01). Geneva WHO. 2005;4-11.

112. Islam M, Islam M. A study on vaccine cold chain monitoring. J Preven Soc Med. 1993;12:53-9.

113. Cheriyan E. Monitoring the vaccine cold chain. Arch Dis Child. 1993;69(5):600-1.

114. Rogers B, Dennison K, Adepoju N, Dowd S, Uedoi K. Vaccine cold chain: part 2. Training personnel and program management. AAOHN J Off J Am Assoc Occup Health Nurses. 2010;58(9):391-400.

115. Carr C, Byles J, Durrheim D, others. Practice nurses best protect the vaccine cold chain in general practice. Aust J Adv Nurs. 2009;27(2):35.

116. von Hedenström M, Kahler W. The cold chain from manufacturer to vaccinator: experiments and experiences. Vaccine. 1992;10(13):949-51.

117. World Health Organization. Global Programme for Vaccines and Immunisation, Expanded Programme on Immunisation. Module; 1998.

118. Knoll MD, Park DE, Johnson TS, Chandir S, Nonyane BAS, Conklin L, et al. Systematic review of the effect of pneumococcal conjugate vaccine dosing schedules on immunogenicity. Pediatr Infect Dis J. 2014;33:S119-29.

119. Gregson AL, Edelman R. Does antigenic overload exist? The role of multiple immunizations in infants. Immunol Allergy Clin N Am. 2003;23(4):649-64.

120. Hess G, Hingst V, Cseke J, Bock HL, Clemens R. Influence of vaccination schedules and host factors on antibody response following hepatitis $B$ vaccination. Eur J Clin Microbiol Infect Dis. 1992;11(4):334-40.

121. Bruguera M, Rodicio JL, Alcazar JM, Oliver A, Del Rio G, Esteban-Mur R. Effects of different dose levels and vaccination schedules on immune response to a recombinant DNA hepatitis $B$ vaccine in haemodialysis patients. Vaccine. 1990;8:547-9.

122. Poland GA. Variability in immune response to pathogens: using measles vaccine to probe immunogenetic determinants of response. Am J Hum Genet. 1998;62(2):215-20.

\section{Submit your next manuscript to BioMed Central and we will help you at every step:}

- We accept pre-submission inquiries

- Our selector tool helps you to find the most relevant journal

- We provide round the clock customer support

- Convenient online submission

- Thorough peer review

- Inclusion in PubMed and all major indexing services

- Maximum visibility for your research

Submit your manuscript at www.biomedcentral.com/submit
Biomed Central 